\title{
ジヒドリドロジウム錯体-テトラヒドロフラン系による メタクリル酸メチルの重合
}

\author{
亀田 徳幸*1 ・服部 雅*1
}

(受付 1985 年 2 月 18 日・棤查終了 1985 年 4 月 8 日)

\begin{abstract}
要 旨 ジヒドリドロジウム錯体 $\left[\mathrm{RhH}_{2}(\mathrm{PhNNNPh})\left(\mathrm{PPh}_{3}\right)_{2}\right]$-テトラヒドロフラン (THF) 䒺によ るメタクリル酸メチル (MMA) の重合を動力学的に梌时した。重合速度 $\left(R_{\mathrm{p}}\right)$ は次式に從らことが わかった。 $R_{\mathrm{p}}=k\left[\mathrm{RhH}_{2}(\mathrm{PhNNNPh})\left(\mathrm{PPh}_{3}\right)_{2}\right]^{0.25} \cdot[\mathrm{THF}]^{1.0} \cdot[\mathrm{MMA}]^{1.0}$

$R_{\mathrm{p}}$ に対する開始绪の成分である $\mathrm{RhH}_{2}(\mathrm{PhNNNPh})\left(\mathrm{PPh}_{3}\right)_{2}$ の䈨度の次数は 0.5 よりも低く，一 次ラジカル停止であることを示している，モノマー源度が塔加するとともに得られるボリメタクリル 酸メチルの分子直し直線的に增加ナる，以上の結果と，重合系の紫外可視吸収スペクトルの测定結果 から重合機楼を考察した。
\end{abstract}

\section{1 楮}

前報1に和いて，著者らはジヒドリドロジウム錯体で

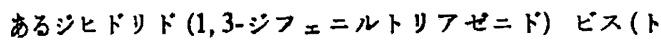
リフェニルホスフィン) ロジウム (III) $\left[\mathrm{RhH}_{2}(\mathrm{PhNNN}\right.$ $\left.\mathrm{Ph})\left(\mathrm{PPh}_{3}\right)_{2}\right]$ は単独ではビニル化合物の重合開始剤とし ての性質を示さないか，これにェーテル結合を持つ化合 物を組み合わせると重合開始活性を示すことを報告し た. ビニル化合物としてメタクリル酸メチル(MMA)を 用い, $\mathrm{RhH}_{2}(\mathrm{PhNNNPh})\left(\mathrm{PPh}_{3}\right)_{2}$ とテトラヒドロフラン (THF) を組及合わせた系の重合活性が最す大きいこと がわかった．この開始采の重合形式はラシカル重合であ ク，また得られた見かけの活性化エネルギーから考える とレドックス系開始郕であると思われる。

本報では， $\mathrm{RhH}_{2}(\mathrm{PhNNNPh})\left(\mathrm{PPh}_{3}\right)_{2}$ と THF による MMA の重合を動力学的に調へるととすに分光学的な 手法を用いて，その重合機構について検討を加えた結果 を報告する。

\section{2 实験}

\section{1 試料}

モノマーである MMA は常法により精製し，等素気 楛中て減王蒸留したすのを用いた。溶媒として用いた THF 及びペンゼンは和光純薬工業(姝) 製スペクトル測 定用のすのを使用した．重合物の沈殿剤であるメタノー 山試莱一級を蒸留して用いた。 $\mathrm{RhH}_{2}(\mathrm{PhNNNPh})$ $\left(\mathrm{PPh}_{3}\right)_{2}$ 恃既報1) 飞従って合成したものを使用した。

\footnotetext{
*! 日本大学理工学部（亚274 船榣市習志野台 7-24-1)
}

\section{2 实聁方法}

重合は容積約 $30 \mathrm{ml}$ のガラス反応管を用いた。 ただ し，紫外可視吸収スペクトルの測定のときに限り三方コ ック付きガラス反応管を使用した．あらかじめ窒素ガス 圈換した反応管内に $\mathrm{RhH}_{2}(\mathrm{PhNNNPh})\left(\mathrm{PPh}_{3}\right)_{2}$, 溶媒及 び MMA の順に加え再び反応管内を窒素ガス圆換した 後, 佰温油浴中で所定時間重合を行った，その後，反応 混合物を多量のメタノール中にそそぎ込み，重合体を沈 殿させた. 重合体を汇別し、メタノールで洗浄後室温中 で佰量に達するまで減圧乾燥し，重量法により重合収率 を算出した。

生成したポリメタクリル酸メチル (PMMA) の平均分 子量の測定は既報1)に従って行った。

2.3 紫外可視吸収スペクトル

紫外可視吸収スペクトルは Beckmann 社製 Acta CIII型自記分光光度計を使用して，室温で測定した．各時 間ごとに三方ュックの一方から窒菜ガスを通しながら， 反応管内の反応物を注射器で取り出し，厚さ $2 \mathrm{~mm} の$ セルを用いてスペクトルの変化を調べた．対照用セルに は重合に用いた試料溶液と同一瀑度の MMA と THF との混合溶液を入れた。

\section{3 結果と考察}

\section{1 反忘次数}

既報1) に批いて， $\mathrm{RhH}_{2}(\mathrm{PhNNNPh})\left(\mathrm{PPh}_{3}\right)_{2}$-THF 手 による MMA の重合を $50 \sim 80^{\circ} \mathrm{C}$ と温度変化させて重 合を行った結果，重合収率はいずれの温度においてる時 間ととすに直線的に增加すること，また Arrhenius プ ロットも一直線上にのることがわかった。この結果にす 


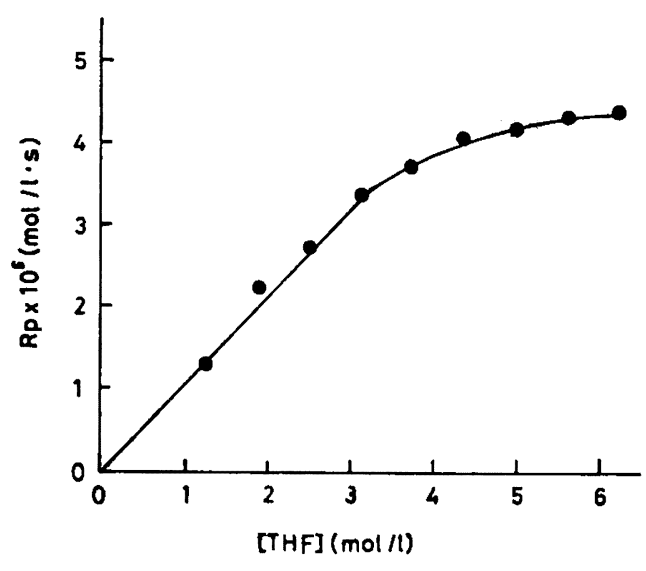

Fig. 1. Relationship between $R_{\mathrm{p}}$ and the concentration of THF: $\mathrm{RhH}_{2}(\mathrm{PhNNNPh})\left(\mathrm{PPh}_{3}\right)_{2}$, $3.3 \times 10^{-4} \mathrm{~mol} / l$; MMA, $5 \mathrm{ml}$; total volume, $10 \mathrm{ml}$ in benzene; temp., $50^{\circ} \mathrm{C}$.

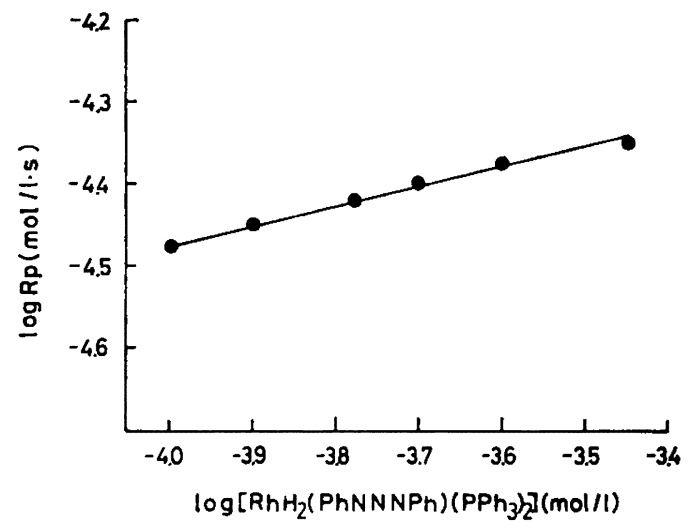

Fig. 2. Relationship between $R_{\mathrm{p}}$ and the concentration of $\mathrm{RhH}_{2}(\mathrm{PhNNNPh})\left(\mathrm{PPh}_{3}\right)_{2}$ : $\mathrm{MMA}$, $5 \mathrm{ml}$; THF, $5 \mathrm{ml}$; temp., $50^{\circ} \mathrm{C}$.

とづき, 本研究の重合速度 $\left(R_{\mathrm{p}}\right)$ の測定は $50^{\circ} \mathrm{C}$ で行っ た.

MMA, $5 \mathrm{ml}$ 及び $\mathrm{RhH}_{2}\left(\mathrm{PhNNNPh}\left(\mathrm{PPh}_{3}\right)_{2}\right.$ 濃度 3.3 $\times 10^{-4} \mathrm{~mol} / l$ を一定に保ち，全量が $10 \mathrm{ml}$ になるよら にペンゼンを希秎放として用い，THF 港度を変化させ て重合を行った， $R_{\mathrm{p}}$ を $\mathrm{THF}$ 濃度に対してプロットし たものを Fig. 1 に示す.

Fig. 1 の結果から, THF 演度が $3.12 \mathrm{~mol} / l$ 以下の ところでは THF の添加ととすに重合収率は直線的に増 加し， $R_{p}$ は THF 浱度の 1 乗に比例することが認めら れるが、これより高算度では重合収率はほとんと増加せ ず,一定になることがわかった，以後の実検は THF 溶 媒中で行った。

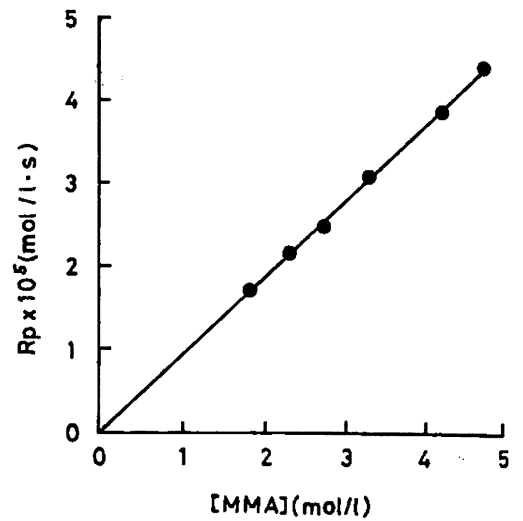

Fig. 3. Relationship between $R_{\mathrm{p}}$ and the concentration of $\mathrm{MMA}: \mathrm{RhH}_{2}(\mathrm{PhNNNPh})\left(\mathrm{PPh}_{3}\right)_{2}$, $3.3 \times 10^{-4} \mathrm{~mol} / l$; MMA + THF, $10 \mathrm{ml}$; temp., $50^{\circ} \mathrm{C}$.

MMA 港度及び THF 湛度を一定に保って, $\mathrm{RhH}_{2}$ $(\mathrm{PhNNNPh})\left(\mathrm{PPh}_{3}\right)_{2}$ 港度を変化させて重合を行い, $R_{\mathrm{p}}$ の対数と $\mathrm{RhH}_{2}(\mathrm{PhNNNPh})\left(\mathrm{PPh}_{3}\right)_{2}$ の対数の成係をフ ロットした結果を Fig. 2 に示す. Fig. 2 の直線の㑯き から， $R_{\mathrm{p}}$ は $\mathrm{RhH}_{2}(\mathrm{PhNNNPh})\left(\mathrm{PPh}_{3}\right)_{2}$ 港度の 0.25 乗 に比例することが陻められる.

つぎに $\mathrm{RhH}_{2}(\mathrm{PhNNNPh})\left(\mathrm{PPh}_{3}\right)_{2}$ 灌度及び THF 度を一定に保ち，MMA 㩐度を变化させて重合を行う と, Fig. 3 にみられるよらに $R_{\mathrm{p}}$ は MMA 濩度の1乗 に比例寸ることがわかる.

以上の結果から， $\boldsymbol{R}_{\mathrm{p}}$ は次式のように示される.

$R_{\mathrm{p}}=k\left[\mathrm{RhH}_{2}(\mathrm{PhNNNPh})\left(\mathrm{PPh}_{3}\right)_{2}\right]^{0.25} \cdot[\mathrm{THF}]^{1.0}$.

$$
[\mathrm{MMA}]^{1.0}
$$

\section{2 吸収スペクトルの則定}

$\mathrm{RhH}_{2}(\mathrm{PhNNNPh})\left(\mathrm{PPh}_{3}\right)_{2}-\mathrm{THF}$ 釆による MMA の 重合に伴 $5 \mathrm{RhH}_{2}(\mathrm{PhNNNPh})\left(\mathrm{PPh}_{3}\right)_{2}$ の錯体の変化を 调べるため，紫外可視吸収スペクトルの测定を行った。 $\mathrm{RhH}_{2}\left(\mathrm{PhNNNPh}_{(\mathrm{PPh}}\right)_{2}$ の THF 溶液の吸収スペクト ルの極大吸収は 285 及び $445 \mathrm{~nm}$ 付近に認められる. これに MMA を加えた場合 Fig. 4 に示すように 310 及び $445 \mathrm{~nm}$ 付近に吸収が認められ，短波長側の吸收が 約 $25 \mathrm{~nm}$ 長波長側に移動している. しかし長波長似の 吸収の位置は変わらない。これを $50^{\circ} \mathrm{C} て ゙$ 加熱すると， 時間の経過ととすに $445 \mathrm{~nm}$ の吸収の強度は增加する。 しかし短波長側の吸収は注とんど変化が翟められない。

\subsection{MMA 湌度と分子量との関係}

$\mathrm{RhH}_{2}(\mathrm{PhNNNPh})\left(\mathrm{PPh}_{3}\right)_{2}-\mathrm{THF}$ 系による MMA の 重合で得られる PMMA の分子显に対する MMA 港度 の依存性について検討した結果を Fig. 5 に示す.この 因から，MMA 洤度の增加ととすに PMMA の分子企 


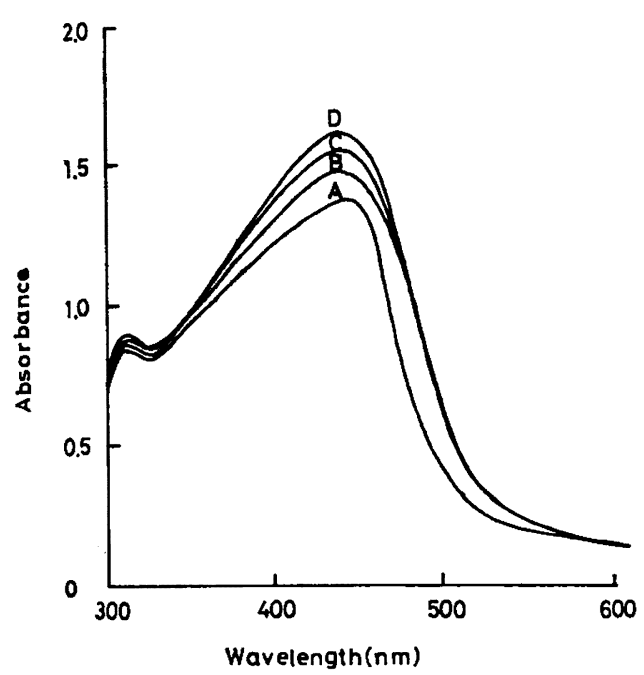

Fig. 4. Change in absorption spectrum with time of the MMA polymerization with a $\mathrm{RhH}_{2}(\mathrm{PhNNNPh})\left(\mathrm{PPh}_{3}\right)_{2}$-THF system: $\mathrm{RhH}_{2}$ $(\mathrm{PhNNNPh})\left(\mathrm{PPh}_{3}\right)_{2}, \quad 3.3 \times 10^{-4} \mathrm{~mol} / \mathrm{l} ; \mathrm{MMA}$, $5 \mathrm{ml}$; THF, $5 \mathrm{ml}$; temp., $50^{\circ} \mathrm{C}$; time(h): A, 0; B, 1; C, 2; D, 3.

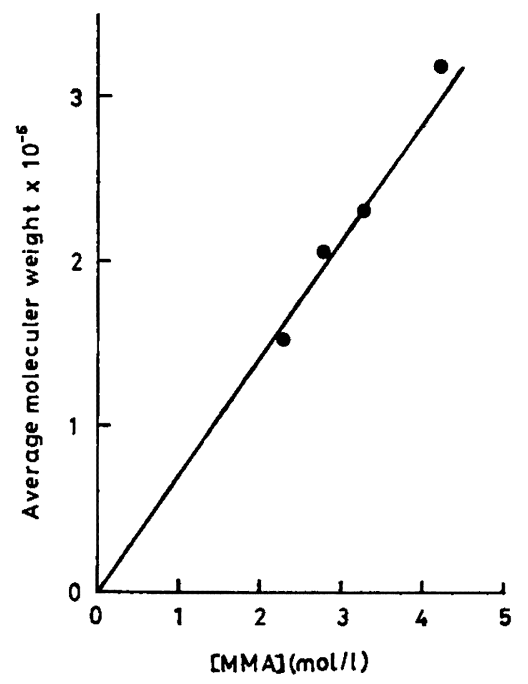

Fig. 5. Effect of concentration of MMA on the average molecular weight of PMMA: $\mathrm{RhH}_{2}(\mathrm{PhNNNPh})\left(\mathrm{PPh}_{3}\right)_{2}, 3.3 \times 10^{-4} \mathrm{~mol} / l ; \mathrm{MMA}$ +THF, $10 \mathrm{ml}$; temp., $50^{\circ} \mathrm{C}$; time, $1 \mathrm{~h}$.

\section{る直線的に增加することがわかる.}

\section{4 正合機棈}

式 (1) に示したように, $\mathrm{RhH}_{2}(\mathrm{PhNNNPh})\left(\mathrm{PPh}_{8}\right)_{2}-$ THF 系による MMA の重合の $R_{\mathrm{p}}$ は $\mathrm{RhH}_{2}(\mathrm{PhNNN}$
$\mathrm{Ph})\left(\mathrm{PPh}_{3}\right)_{2}$ の 0.25 次に比例することがわかった. THF 算度に関しては 1 次であるが，前報》で述べたように， THF が存在しないと重合が起こらないことから，重合 開始䠼の生成時に THF が関与していることは明らかで ある.

この開始系はラジカル重合であることは前報 ${ }^{2}$ で確か められている. 一般にラジカル重合における $R_{\mathrm{p}}$ は開始

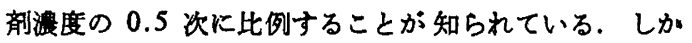
し,この開始系はこれよりる低い值を示し，きわめて特 徵的である.

このよらに低い值を示す例として，エフェドリン銅錯

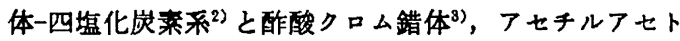
ナートコバルト錯体") 及びロジウムホスフィン錯体り) の それぞれの有機過酸化物系等金属錯体を含む二元系レッ

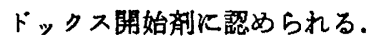

紫外可視吸収スペクトルの測定結果から $\mathrm{RhH}_{2}(\mathrm{Ph}$ NNNPh) $\left(\mathrm{PPh}_{3}\right)_{2}$ をTHF に溶かした溶液に MMA を 加えると短波長側の吸収極大の移動が㤎められる.この ことから MMA を加えることにより中心金属が影督を 受けて配位子交換を促進しやすい状態になっていること が予想される.すでにロジウム (I) ホスフィン錯体で ある $\mathrm{RhCl}(\mathrm{CO})\left(\mathrm{PPh}_{3}\right)_{2} \rightleftharpoons\left[\mathrm{Rh}\left(\mathrm{Ph}_{2} \mathrm{PCH}_{2} \mathrm{CH}_{2} \mathrm{PPh}_{2}\right)_{2}\right] \mathrm{C}^{\mathrm{l}}$ の奄荷移動吸収帯が約 $400 \mathrm{~nm}$ に認められることが報告 されている゚. この事実から，重合時間の経過ととすに $445 \mathrm{~nm}$ の吸収極大の 強度が増加することは $\mathrm{RhH}_{2}(\mathrm{Ph}$ $\mathrm{NNNPh})\left(\mathrm{PPh}_{3}\right)_{2}$ のロシ்ウムの原子価が 3 価から 1 価に 変わり, 還元的脱離反応が起きていると推定される. 更 に，この $445 \mathrm{~nm}$ の吸収強度の增加が長時間にわたって 続いていることは，還元的脱離反応がかなり遟い反応で あることを示している. この反応が継続している間はモ ノマーを重合させる一次ラジルル発生が続き，その湄 度は低いと思われる.このことは，前報1)で報告したよ らに得られるボリマーの重合度は重合収率に烕係なく一 定となること及び重合収率は重合時間とともに直線的に 増加する事実から解釈することがでさる。

停止反応については動力学の測定結果から $\mathrm{RhH}_{2}(\mathrm{Ph}$ $\mathrm{NNNPh})\left(\mathrm{PPh}_{3}\right)_{2}$ 濃度の次数が 0.5 次より低い值が得ら れたことから, 生長ポリマーラジカル間での二分子停止 反応は起こりにくいと思われる. エフェドリン銅錯体一 四塩化炭素系”酶酸ク口ム一有機過酸化物系”におい て金属錯体が停止反応に関与していることが報告されて いる. この重合系む同様に $\mathrm{RhH}_{2}(\mathrm{PhNNNPh})\left(\mathrm{PPh}_{8}\right)_{2}$ が 関与した一次ラジカルと生長ポリマーラジカルとの二分 子停止反応すなわち一次ラジカル停止による停止反応が 主に起きているものと推定される.

$\mathrm{Knoth}^{7)}$ によれば, $\mathrm{RhH}_{2}(\mathrm{PhNNNPh})\left(\mathrm{PPh}_{3}\right)_{2}$ の THF 溶液中で エチレンを反応させて $\mathrm{Rh}(\mathrm{PhNNNPh})$ $\left(\mathrm{PPh}_{3}\right)_{2} \cdot 2 \mathrm{THF}$ を得ていることから，この重合開始系に 
おいても $\mathrm{RhH}_{2}(\mathrm{PhNNNPh})\left(\mathrm{PPh}_{3}\right)_{2}$ 中の $\mathrm{H}^{-}$配位子が 開始郕に関与していることは明らかである。この $\mathrm{H}^{-}$配 位子を水秦ラジカルとしてモノマーか引き抜いて開始反 応を起こす可能性もあるが，紫外可視吸収スヘクトルの 測定結果において MMA を加えると短波長側の吸収の 移動が認められることから，重合開始剤となるラジカル の生成にはモノマーが関与していると考えられる. Chan 5 $5^{8)}$ は $\left[\mathrm{Rh}\left(\mathrm{Ph}_{2} \mathrm{PCH}_{2} \mathrm{CH}_{2} \mathrm{PPh}_{2}\right)\right]^{+}$とよる(Z)- $\alpha-$ アセトアミド桂皮酸メチル (MAC) の水菜化の中間体と して錯体に基貿が配位した RhHS $\left(\mathrm{Ph}_{2} \mathrm{PCH}_{2} \mathrm{CH}_{2} \mathrm{PPh}_{2}\right)$ MAC (S は溶媒を示す) を得ている.

以上のことから考えて, この重合機䅹は $\mathrm{RhH}_{2}(\mathrm{Ph}$ $\mathrm{NNNPh})\left(\mathrm{PPh}_{3}\right)_{2}$ が，市ず初に，配位子である 1,3-シ フェニルトリフぜニドの部分的解離により配位子をあ け，そこに THF か配位したのち，THF とモノマーと の配位子の交解が起こる. 更にモノマーは配位子である $\mathrm{H}^{-}$の一つを引き抜き，口ジウムーフルキル結合の形成 が起こり, 活性化され，ロジウムーフルキル結合のホモ リチックな分解により重合活性なラジカルが生成し，開 始反応か起こる。あいた配位座には扰そらく THF が入 り，そのさい中間体としてもノヒドリドロジウム錯体の 形成が考えられる.これがモノマーと反応すれば，再び ロジウムーアルキル結合を持った錯体が形成され，開始 反応が加わる可能性もある.

停止反応については生長ポリマーラジカルが中間体の モノヒドリドロジウム錯体中の配位子である $\mathrm{H}^{-}$を水菜
ラジカルとして引き抜くか，あるい怢ロジウムーアルキ ル結合を持った錯体のアルキル基を引き抜くことによる 停止, 更にロジムムーアルキル結合のホモリチックな分 解により重合活性なラジカルと不活性なラジカルが生成 し, 前者は重合の開始に作用し，後者は停止に作用する ことす考えられるが，いずれとよるのかは現在のところ 明らかでない，しかし，いずれの場合も錯体のあいた医 位座に再び THF が配位し, 重合不活性な THF の配 位したロジゥム錯体の形成が考えられる。

$\mathrm{RhH}_{2}(\mathrm{PhNNNPh})\left(\mathrm{PPh}_{\mathrm{g}}\right)_{2}$ の反応機構の詳細について は不明であり更に検討する必要がある.

\section{文献}

1）色田徳幸，服部 雅，高分子输文集，41，679 (1984).

2) J. Barton and M. Lazar, Makromol. Chem., 124, 38 (1969).

3) M. Lee and Y. Minoura, J. Chem. Soc., Faraday Trans. 1, 74, 1726 (1978).

4) Z. Osawa, K. Kobayashi, and Y. Ogiwara, J. Macromol. Sci-Chem., A6 1665 (1972).

5) N. Kameda and E. Ishii, Makromol. Chem., 184, 1901 (1983).

6) G.L. Geoffray, H. Isci, J. Litrenti, and W.R. Mason, Inorg. Chem., 16, 1950 (1977).

7) W.H. Knoth, Inorg. Chem., 12, 38 (1973).

8) A.S.C. Chan and J. Halpern, J. Am. Chem. Soc., 102, 838 (1980).

\section{Polymerization of Methyl Methacrylate with a Dihydridorhodium Complex-Tetrahydrofuran System}

Noriyuki KaMEDA*1 and Miyabi HATTORI*1

*1 Department of Chemistry, College of Science and Technology, Nihon University (24-1, Narashinodai 7-chome, Funabashi, 274 Japan)

The kinetics of polymerization of methyl methacrylate (MMA) with a dihydridorhodium complex $\left[\mathrm{RhH}_{2}(\mathrm{PhNNNPh})\left(\mathrm{PPh}_{8}\right)_{2}\right]$-tetrahydrofuran (THF) system was studied. The rate of polymerization $\left(R_{\mathrm{p}}\right)$ was expressed by the following equation:

$$
R_{\mathrm{p}}=k\left[\mathrm{RhH}_{2}(\mathrm{PhNNNPh})\left(\mathrm{PPh}_{3}\right)_{2}\right]^{0.26} \cdot[\mathrm{THF}]^{1.0} \cdot[\mathrm{MMA}]^{1.0}
$$

The kinetics of polymerization of MMA were different from that of a conventional free-radical polymerization. The kinetic order for initiator component $\mathrm{RhH}_{2}(\mathrm{PhNNNPh})\left(\mathrm{PPh}_{8}\right)_{2}$ was smaller than 0.5 , indicating a primary radical termination. The molecular weight of poly(methyl methacrylate) increased linearly with increasing monomer concentration.

From these results as well as the data of the ultraviolet and visible spectroscopy, a possible polymerization mechanism was proposed.

KEY WORDS Kinetics / Methyl Methacrylate / Polymerization / $\mathrm{RhH}_{2}\left(\mathrm{PhNNNPh}\left(\mathrm{PPh}_{\mathbf{8}}\right)_{\mathbf{2}} /\right.$ Tetrahydrofuran / Primary Radical Termination /

(Received February 18, 1985: Accepted April 8, 1985)

[Kobunshi Ronbunshu, 42 (8), 485-488 (1985)] 